\title{
HOW CAN EXISTING GROUND-BASED PROFILING INSTRUMENTS IMPROVE EUROPEAN WEATHER FORECASTS?
}

\author{
A. J. Illingworth, D. Cimini, A. Haefele, M. Haeffelin, M. Hervo, S. Kotthaus, \\ U. Löhnert, P. Martinet, I. Mattis, E. J. O’Connor, and R. Potthast
}

Observations of profiles of winds, aerosols, clouds, temperature, and humidity in the lowest few kilometers of the atmosphere from networks of ceilometers, Doppler wind lidars, and microwave radiometers are starting to flow in real time to forecasting centers in Europe.

$\mathrm{T}$ he high-resolution $(1 \mathrm{~km})$ forecasting models that are now run operationally by many European national weather services promise to provide increasingly accurate high-resolution forecasts of impending hazardous weather, ranging from flash floods to episodes of poor air quality. The World Meteorological Organization (WMO) guidance for numerical weather prediction (NWP) applications highlights the need for wind, temperature, and humidity profiles, especially in cloudy areas. ${ }^{1}$ Satellites can provide data in the upper troposphere, but if this promise is to be fulfilled, in particular for short-range forecasts, a new generation of highdensity observations through the lower few kilometers of the atmosphere, including the boundary layer, is required in real time. This region close to the ground is particularly difficult to observe with satellites because of the frequent occurrence of clouds and, for passive instruments, the broad weighting functions and the effects of the variable albedo or brightness temperature of the surface.

Illingworth et al. (2015) noted the potential of ground-based networks of automatic low-power backscatter lidars/ceilometers [automatic lidar and ceilometer (ALC)], ${ }^{2}$ Doppler wind lidars (DWLs), and microwave radiometers (MWRs) to supply realtime observation to forecast centers. In this paper, we report recent developments in the exploitation of these networks. Observations of profiles of aerosols, clouds, winds, temperature, and humidity in the lowest few kilometers of the atmosphere in Europe are now starting to flow in real time to forecasting centers. This has been achieved as a result of collaboration between a European Cooperation in Science and Technology (COST) action (see sidebar) "Toward Operational Ground-Based Profiling with ALCs,

\footnotetext{
${ }^{1}$ See WMO statements of guidance for high-resolution and global NWP online (at www.wmo.int/pages/prog/www/OSY/SOG /SoG-HighRes-NWP.pdf; www.wmo.int/pages/prog/www/OSY/SOG/SoG-Global-NWP.pdf).

${ }^{2}$ Ceilometers were originally conceived to measure cloud-base altitude only, but today, the sensitivity of these instruments is sufficient to provide profiles of backscattered power from aerosols and clouds. Hence, a new terminology has been proposed that combines automatic low-power lidars and ceilometers into ALCs.
} 
DWLs, and MWRs for Improving Weather Forecasts" (TOPROF; www.cost.eu/COST_Actions/essem /ESI303) and European National Meteorological Services (EUMETNET), an organization that provides a framework to enable the European weather services to work together, share ideas and best practices, and share the cost of major infrastructure investments. The EUMETNET Composite Observing System (EUCOS) is responsible for developing an observing system for Europe serving the needs of regional NWP. One of EUMETNET's programs is the EUMETNET Profiling Program (E-PROFILE), which originally involved only radar wind profilers but has been extended to include ALC networks and more recently is incorporating DWLs with a projected extension to distribute MWR data. The TOPROF action ran from October 2013 to October 2017 with financial support from the European Union and was responsible for setting up common calibration techniques, operating procedures, deriving error characteristics, developing retrieval algorithms, and ensuring homogeneous and reliable data quality for the three classes of instruments, whereas EUMETNET through E-PROFILE is involved in the networking and near-real-time distribution of observations to the national weather services.

The ALCs under investigation in the E-PROFILE network transmit short pulses of laser radiation with wavelengths $532, \sim 910$, or $1,064 \mathrm{~nm}$ and receive a

AFFILIATIONS: ILLINGWORTH-Department of Meteorology, University of Reading, Reading, United Kingdom; CIMINICNR-IMAA, Potenza, and Center of Excellence in Telesensing of Environment and Model Prediction of Severe Events, University of L'Aquila, L’Aquila, Italy; Haefele AND HeRvo-MeteoSwiss, Payerne, Switzerland; Haeffelin and Kotthaus-L'Institut Pierre Simon Laplace, CNRS, Ecole Polytechnique, Palaiseau, France; LöHNERTInstitute for Geophysics and Meteorology, University of Cologne, Cologne, Germany; MARTINET-CNRM, Université de Toulouse, Météo-France, CNRS, Toulouse, France; MATTIS-Observatorium Hohenpeißenberg, Deutscher Wetterdienst, Hohenpeissenberg, Germany; O'CONNOR-Finnish Meteorological Institute, Helsinki, Finland; POTTHAST-Deutscher Wetterdienst, Offenbach, Germany CORRESPONDING AUTHOR: Anthony J. Illingworth,

a.j.illingworth@reading.ac.uk

The abstract for this article can be found in this issue, following the table of contents.

DOI:10.II75/BAMS-D-17-023I.I

In final form 23 October 2018

C2019 American Meteorological Society

For information regarding reuse of this content and general copyright information, consult the AMS Copyright Policy.

This article is licensed under a Creative Commons Attribution 4.0 license. backscattered signal with a delay that provides range information. The raw data are averaged to $15-30-\mathrm{m}$ vertical resolution and $15-60 \mathrm{~s}$ in time. Examples of the use of attenuated backscatter profiles include characterizing clouds, aerosols, dust, fog, and volcanic ash as discussed in more detail in the ALC section, the last two being especially important for air traffic control. At present, attenuated backscatter profiles from over 265 ALCs in 19 countries are being distributed by EUMETNET E-PROFILE in near-real time to national weather services and can be viewed online (at http://eumetnet.eu/e-profile/). These data are homogenized and calibrated using the developments carried out in TOPROF.

Figure 1 represents the map of E-PROFILE stations in green and stations that will be integrated before the end of 2018 in blue: ALCs that are present in Europe but not yet integrated into E-PROFILE are in red [data from Deutscher Wetterdienst's (DWD) ceilomap; www.dwd.de/ceilomap]. In June 2018, the Saddleworth Moor fire near Manchester, United Kingdom, injected large quantities of smoke into the atmosphere. This smoke was transported over the United Kingdom and Europe and measured by the E-PROFILE network. The measurements from 26 to 28 June at five E-PROFILE stations are displayed in Fig. 1. Aerosol layers are visible in the free troposphere (at altitudes between 2 and $5 \mathrm{~km}$ ). Measurements above thick clouds (represented with black dots) appear as white vertical stripes because the laser beam is fully attenuated. These measurements are also visible on the E-PROFILE website and clearly illustrate the capabilities of the network in monitoring aerosol layers over Europe.

In contrast to ALCs that have been in use for many years, DWLs have undergone recent development using solid-state fiber-optic technology at a wavelength of $\sim 1.5 \mu \mathrm{m}$. The type of DWL being incorporated into the E-PROFILE network obtains the radial Doppler shift of the backscattered signal from aerosol or cloud particles in the direction of the beam using the high-pulse-rate heterodyne technique. From the radial Doppler velocities, the vertical structure of winds, wind shear, levels of turbulence, inference of the maximum gusts, properties of lowlevel jets, and classification of the state of the boundary layer can be obtained. The minimum range is typically $50-90 \mathrm{~m}$, with the maximum range varying from 2 to $10 \mathrm{~km}$; in practice, the sensitivity of most instruments usually limits the observations to within the boundary layer where there are sufficient aerosols. Wind measurements are not possible inside or above optically thick clouds or in heavy rain. 
Ground-based MWRs measure the downwelling thermal emission in the microwave part of the electromagnetic spectrum originating from Earth's atmosphere and the cosmic background. The radiance observations are commonly expressed as an equivalent brightness temperature $T_{B}$, from which estimates of atmospheric temperature profiles (from oxygen absorption from 55 to $60 \mathrm{GHz}$ ) and humidity profiles (from water vapor absorption around $22 \mathrm{GHz}$ ) as well as column-integrated water vapor (IWV) and liquid water path (LWP) can be inferred during nonprecipitating conditions. Valid temperature profiles can also be inferred in the presence of low to moderate precipitation. The MWR profiling capability in the lowest $2 \mathrm{~km}$ of the atmosphere is proving to be valuable because of the poor sampling by other sensors (e.g., from satellites).

All these instruments are rugged and can operate autonomously for long periods, requiring little maintenance and no specialized staff, but how can these new observations contribute to NWP? First, they can be used to check that the parameterization schemes inherent in such models lead to a realistic representation of the current state of the atmosphere. For more

\section{THE TOPROF COST ACTION}

COST is an European Union-funded program that Cenables researchers to set up interdisciplinary research networks in Europe and beyond; 22 European countries participated in the TOPROF action, with researchers from 16 national weather services attending together with representatives from 6 European manufacturers of ALCs, DWLs, and MWRs. Three-day meetings were held twice a year, each with about 50 participants, but most importantly, TOPROF supported 24 separate weeklong visits by individual scientists to other research laboratories, national weather services, or industry, where they tackled specific problems such as changes to calibration procedures, modifications to data processing that resulted in new public releases of software, physical modification of the instruments, and testing of forward models at national weather services. In addition, there were 12 special meetings to plan, execute, and discuss field projects dedicated to comparing the performance of different instruments with various configurations and, in some cases, with independent validation using instrumented towers and/or special radiosonde ascents.
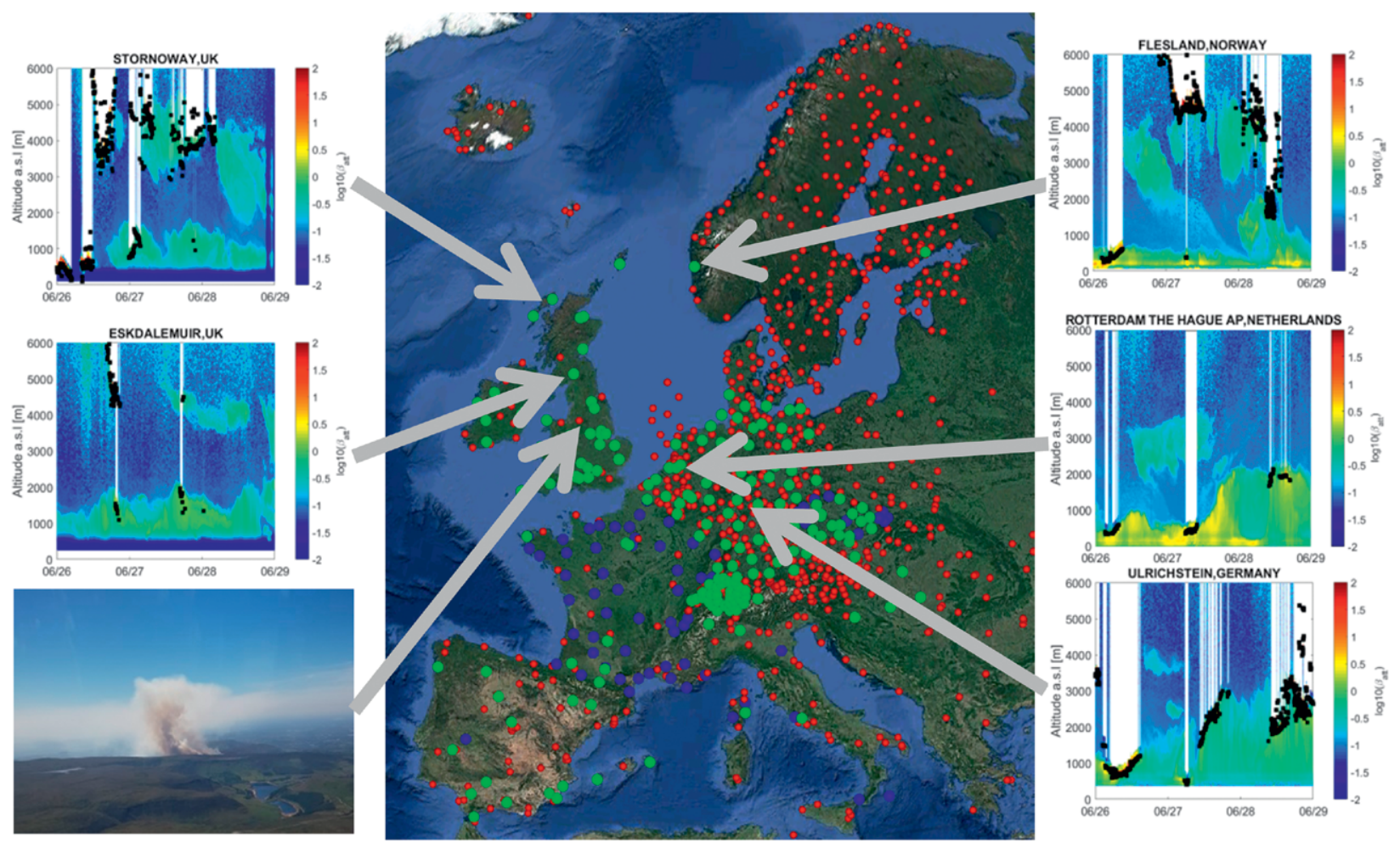

FIG. I. (center) Map of the ALC network (green: operational E-PROFILE stations; blue: stations planned for 2018; red: other ceilometers reported by DWD's ceilomap). (top left),(middle left),(right) Examples of E-PROFILE measurements during the Saddleworth Moor fire near Manchester (26-27 Jun 2018). Five stations are represented: Stornoway, Eskdalemuir, Flesland, Rotterdam, and Ulrichstein. (bottom left) A photograph of the fire (courtesy E. J. O'Connor). 
than 10 years, the Cloudnet project (Illingworth et al. 2007) has used vertically pointing cloud radars, ALCs, and MWRs to derive cloud properties, compared them with the representation of clouds within several operational European forecast models, and produced statistics of the model performance (http://cloudnet .fmi.fi). In Cloudnet, the ALCs were only used to identify cloud base of liquid clouds and the MWRs to derive their liquid water path. A more rigorous approach is to compare the observations $O$ with their representation in the model (the background $B$ ) to obtain the $O-B$ statistics and to check that any biases are sufficiently small and, ideally, that the errors are Gaussian. This procedure is fairly straightforward for the winds from a DWL because the model has a prognostic wind variable. This is not the case for the ALC backscatter signal nor for the brightness temperature from microwave radiometers, so a "forward model" must be used that operates on the prognostic variables within the NWP model to predict the value of the observed parameter, which can then be directly compared with the observation. Once the $O-B$ statistics are deemed to be acceptable, then there is potential for data assimilation whereby the initial state of the model is updated with the observations accounting for the errors in both the observations and the model so that the NWP model can be initialized with the best possible representation of the current state of the atmosphere. A more accurate initial state usually reduces the errors in the forecast.

If the new observations are to be useful, then it is essential that the data are calibrated and unbiased and the quality is homogeneous with known error characteristics. TOPROF's major tasks have been to establish common calibration procedures for the three classes of instruments, common checks on data quality, and independent validation of the veracity of the data. TOPROF has also developed forward models for predicting the ALC and MWR observations from the NWP representation and defined common data formats and protocols for transmitting the data to a central hub from where they can be distributed to the national weather services. Finally, TOPROF has started gathering $O-B$ statistics of model performance and carried out some simple data assimilation trials that indicate a positive impact on the forecast.

ALCS. Figure 2 shows a warm front crossing Germany in the morning of 25 August 2018 as observed at Ulm, Germany, by a Cloud Height Monitor (CHM) 15k ceilometer of the DWD network. The cloud-base height descended from $10 \mathrm{~km}$ at midnight to $2.5 \mathrm{~km}$ at 0800 UTC. Rain started at 0900 UTC, visible as red vertical stripes between the cloud base and the ground. The yellowish horizontal line at $2-\mathrm{km}$ altitude between 1200 and 1500 UTC shows the melting layer (dark band). After the frontal passage (at about 1500 UTC), the steady rain stopped, and the stratiform clouds were replaced by broken cumulus, with some precipitation below cloud base that occasionally reached the ground. Liquid water clouds can be identified by a thin layer with very high backscatter at cloud base followed by rapid extinction of the ceilometer signal, for example, near heights of $2-3 \mathrm{~km}$ at 0000 and 0200 UTC and from 1700 to 2100 UTC, whereas the ceilometer signal penetrates farther into ice clouds. Before the frontal passage, the the atmospheric boundary layer (ABL) was characterized by a significant aerosol load with backscatter values $>1 \mathrm{Mm}^{-1} \mathrm{sr}^{-1}$ up to $\sim 2-\mathrm{km}$ height but was cleaner during the afternoon; this could be due to washout or a different, cleaner air mass. Note the two thin aerosol layers from long-range transport (in yellow) at 8- and 10.5-km altitude after 2200 UTC with backscatter values $\sim 0.5 \mathrm{Mm}^{-1} \mathrm{sr}^{-1}$, possibly from forest fires in North America.

Three classes of ALCs are being used in the E-PROFILE network: CL31 and CL51 from Vaisala measuring at $\sim 910 \mathrm{~nm}, \mathrm{CHM} 15 \mathrm{k}$ from Lufft measuring at $1,064 \mathrm{~nm}$, and Mini Micro Pulse Lidar (MiniMPL) from Sigma Space, measuring at $532 \mathrm{~nm}$. Other ALCs are also exploited at some sites, such as, for example, the CS135 from Campbell Scientific $(910 \mathrm{~nm})$ or the CE370 from Cimel (532 nm). ALCs are characterized by their continuous $24-7$ operation capabilities with high sampling rates. In the low-altitude range, the optical overlap between the emitting (laser) and receiving (telescope) optical components of an ALC changes with altitude. If this overlap function is not well characterized, exploitation of the measurements at low altitude may be restricted. In the far-altitude range, the signal-to-noise ratio may limit the exploitation of the measurements for detecting low-scattering media such as aerosols. Some more sensitive systems may, on the contrary, suffer from saturation because of high-scattering media such as liquid water clouds at short range. Some of these effects can be corrected to improve signal quality. All ALCs must also be calibrated in order to derive quantitatively meaningful attenuated backscatter profiles that can be compared from one instrument to the next and with values predicted from NWP forward models.

1) Determining optical overlap functions. The optical design of CL31 (CL51) instruments yield a near complete overlap around 50 (200) m (e.g., 
Haeffelin et al. 2012; Wiegner et al. 2014). The biaxial lidars like CHM 15k or MiniMPL reach complete optical overlap around $1 \mathrm{~km}$ with very noisy signal below $150-200 \mathrm{~m}$, a region where the optical overlap is close to zero. Hervo et al. (2016) found that the optical overlap function of the CHM 15k is affected by temperature fluctuations. They developed a methodology to determine the temperature dependence and correct for it, yielding precise attenuated backscatter values in the partial overlap region.

2) Correcting signal artifacts. Kotthaus et al. (2016) found signal artifacts in the free troposphere in CL31 attenuated backscatter profiles, characterized by negative values in cloud-free regions due to a shift of the raw data introduced by the system firmware, and developed a method to quantify these artifacts and correct for them. These results convinced Vaisala to release a new firmware for TOPROF that removes the artificial shifts to allow more quantitative exploitation of the CL31 attenuated backscatter profiles.

3) ALC calibration. The signal detected by the ceilometers must be converted into an absolute value of backscatter measured in units of $\mathrm{m}^{-1} \mathrm{sr}^{-1}$. This is best accomplished by using a reference target whose backscatter characteristics are known. One approach uses the known integrated backscatter for a water cloud that totally extinguishes the ceilometer signal; this can be obtained by adding the observed backscatter at each gate within the cloud and adjusting the ceilometer calibration until this integral, after correction for multiple scattering, is equal to $0.027 \mathrm{~m}^{-1}$. For details, see O'Connor et al. (2004). Hopkin et al. (2018) showed that this calibration is accurate to better than $10 \%$ with no significant annual variation. A second approach for photon-counting instruments measuring at $532 \mathrm{~nm}$ or, more commonly, at $1,064 \mathrm{~nm}$ is to use the molecular return as a reference because it is a function of the known air density (Fernald et al. 1972; Klett 1985; Wiegner and Geiß 2012; Baars et al. 2016). The molecular return at $1,064 \mathrm{~nm}$ is small, but photon-counting instruments are able to measure it with sufficiently long averaging times (Wiegner and Geiß 2012; Fig. A2 in
Baars et al. 2016). The method developed within TOPROF relies on averaging the backscatter return for $6 \mathrm{~h}$ on a clear night; sensitivity studies showed that typical accuracies of the calibration are on the order of $10 \%-15 \%$. The calibrations can be up to a factor of 2 different from those supplied by the manufacturer. These two methods are implemented by E-PROFILE to distribute calibrated attenuated backscatter data to national weather services. Wiegner and Gasteiger (2015) propose a method to correct for water vapor absorption for ALC measurements that operate at wavelengths affected by this effect (e.g., 905-910 nm).

4) ALC measurement uncertainties for Lufft and Vaisala due to incomplete optical overlap, signal artifacts, and calibration. These have been estimated using data from a 3-month experiment Ceilometer Performance Experiment at Lindenberg (CeiLinEx), when 12 ALCs were operated side by side (https://ceilinex20I5.de/; Pattantyús-Ábrahám et al. 2017). Figure 3 shows a comparison of raw ALC signal and calibrated attenuated backscatter signal from eight collocated ALCs including Campbell Scientific, Vaisala, and Lufft instruments based on $3 \mathrm{~h}$ of data on 13 August 2015. The profiles show a stable nocturnal boundary layer up to $300 \mathrm{~m}$ and a residual layer up to $750 \mathrm{~m}$. Additionally, there are two lofted aerosol layers (probably Saharan dust) between 1 and $4 \mathrm{~km}$. Figure 3 shows that differences less than $25 \%$ can be expected for calibrated attenuated backscatter, in particular, for altitudes greater than $500 \mathrm{~m}$. Below $500 \mathrm{~m}$, the greater differences between the Lufft and Vaisala 
instruments can be attributed to systematic errors in the overlap function correction. Note also inconsistencies below $250 \mathrm{~m}$ between CL31 and CL51 profiles and between the different Lufft ALCs, confirming that data should be used with great care at such low altitudes. CL31 and CL51 measurements have a lower signal-to-noise ratio than the other instruments so are less sensitive for monitoring lofted aerosol.

Applications using ALC measurements are numerous. Several studies were conducted in the framework of the TOPROF action that resulted in the evaluation of aerosols in atmospheric models based on ALC forward models and $O-B$ statistics (e.g., Warren et al. 2018), providing diagnostics of the atmospheric boundary layer height (Lotteraner and Piringer 2016; Poltera et al. 2017; Kotthaus and Grimmond 2018); supporting warning of fog formation (Haeffelin et al. 2016); and detecting transport of dust, biomass burning, and volcanic ash (Cazorla et al. 2017; Román et al. 2018). Figure 4 shows an example of comparisons between attenuated backscatter observed by an ALC and modeled using the European Centre for Medium-Range Weather Forecasts (ECMWF) Copernicus Atmosphere Monitoring Services (CAMS) forward model. ${ }^{3}$ The observations were performed by a CHM 15k in Valladolid, Spain, and calibrated using the methodology described above. Saharan dust aerosols are clearly visible up to $5 \mathrm{~km}$, both in the observations and the forecasts. The
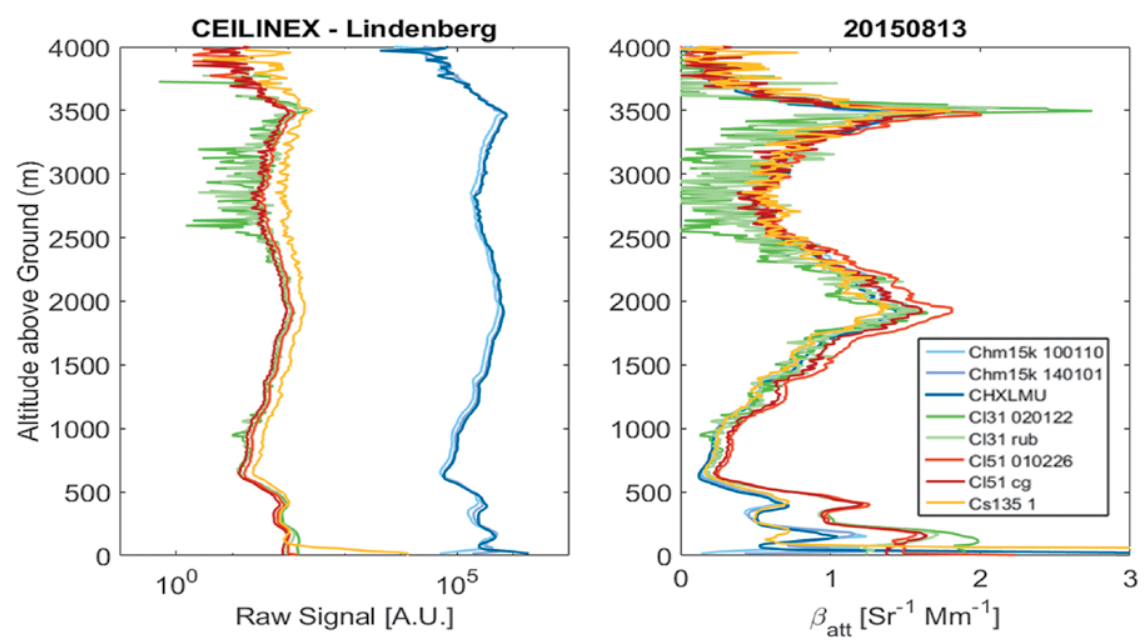

FIG. 3. ALC measurements from eight collocated ALCs, including Campbell Scientific, Vaisala, and Lufft instruments, based on $3 \mathrm{~h}$ of data on 13 Aug 2015 during the CeiLinEx campaign in Lindenberg. (left) Raw instrument signal. (right) Calibrated attenuated backscatter signal $\left(1 \mathrm{Mm}=10^{6} \mathrm{~m}\right)$. Note the increased noise for the CL3I above $2 \mathrm{~km}$ and the divergence of the profiles below $500 \mathrm{~m}$. mean bias for this event is lower than $5 \%$, showing the good agreement between observations and forecasts. Chan et al. (2018) carried out a yearlong comparison of the representation of aerosols within the CAMS model and from the German ceilometer network and found very good agreement with the arrival time and vertical extent of a Saharan dust layer. Figure 5 shows an example of low-altitude ALC-derived information during $3 \mathrm{~h}$ in prefog conditions at the Charles de Gaulle airport near Paris, France. The bottom panel shows the $0-400-\mathrm{m} \mathrm{ALC}$ attenuated backscatter profile, while the top panel provides fog alerts based on Haeffelin et al. (2016). At $0430 \mathrm{~h}$, more than $1 \mathrm{~h}$ before the first alerts, the sky is cloud free (bottom panel), favoring radiative cooling, and the ALC backscatter is quite high, between 50 and $150 \mathrm{~m}$, revealing the presence of large aerosols in a moist atmosphere. At $0550 \mathrm{~h}$, a cloud forms about $100 \mathrm{~m}$ AGL, generating severe-level alerts aloft, and rapidly subsides to the ground, leading to persistent fog after $0645 \mathrm{~h}$, about $1 \mathrm{~h}$ after the first severe-level alerts.

DWLS. The Doppler lidar instruments considered by the TOPROF action were those with sufficient sensitivity and a scanning capability so that the horizontal wind profile could be derived throughout the boundary layer. These included instruments from Halo Photonics (Streamline, Streamline Pro, and Streamline XR) and Leosphere (WindCube 100S, $200 \mathrm{~S}$, and 400S), all configurable to have a maximum range of about $10 \mathrm{~km}$ and range resolution of $50 \mathrm{~m}$ or better. All DWLs considered in TOPROF are full-hemispheric scanning, except for the Halo Photonics Streamline Pro, which can scan within a cone from $70^{\circ}$ above the

\footnotetext{
${ }^{3}$ Developed for the CloudAerosol Lidar with Orthogonal Polarization (CALIOP) lidar data from Cloud-Aerosol Lidar and Infrared Pathfinder Satellite Observations (CALIPSO) satellite in the A-Train, (Benedetti et al. 2009) but looking upward instead of downward. The model carries aerosol type and size, so the optical depth/extinction is calculated, and the assumed lidar ratio converts extinction into the observed value of backscatter.
} 
horizon to zenith and has no external moving parts. One task in TOPROF was to design suitable scanning strategies optimized to extract as much information as possible. The scanning capability is utilized to reconstruct the vertical profile of the horizontal wind from the measured radial components. This can be performed in a similar manner as for radar wind profilers by means of "Doppler beam swinging,"
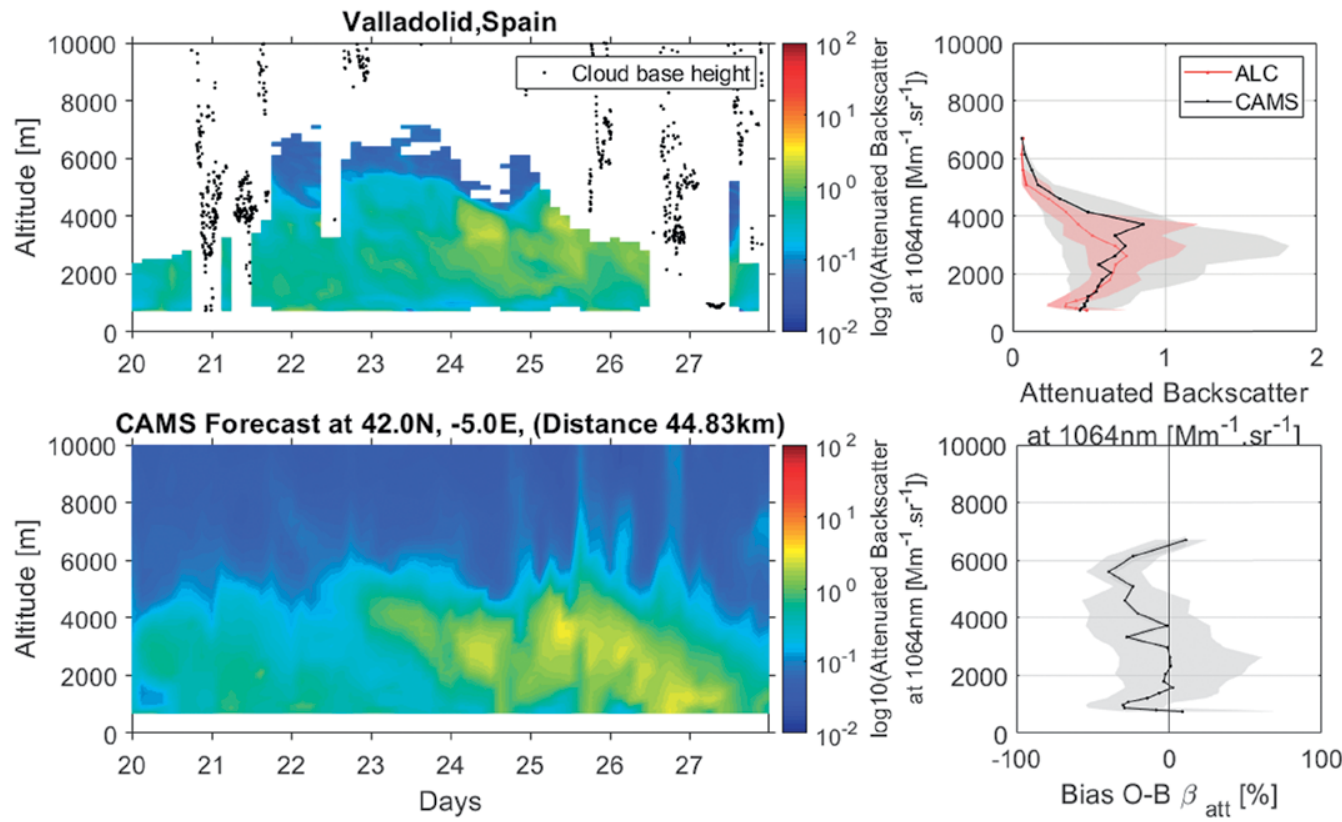

FIG. 4. (top left) Attenuated backscatter measured by the CHM I5k in Valladolid during a Saharan dust event from 20 to 27 Jun 2018. Data above clouds and with SNR lower than 3 are removed. (bottom left) Attenuated backscatter forecast by CAMS model at the closest grid point. (top right) Median attenuated backscatter measured (in red) and forecast (in black). (bottom right) Median of the bias between observations and forecasts. Shading represents 25 th and 75 th percentiles.
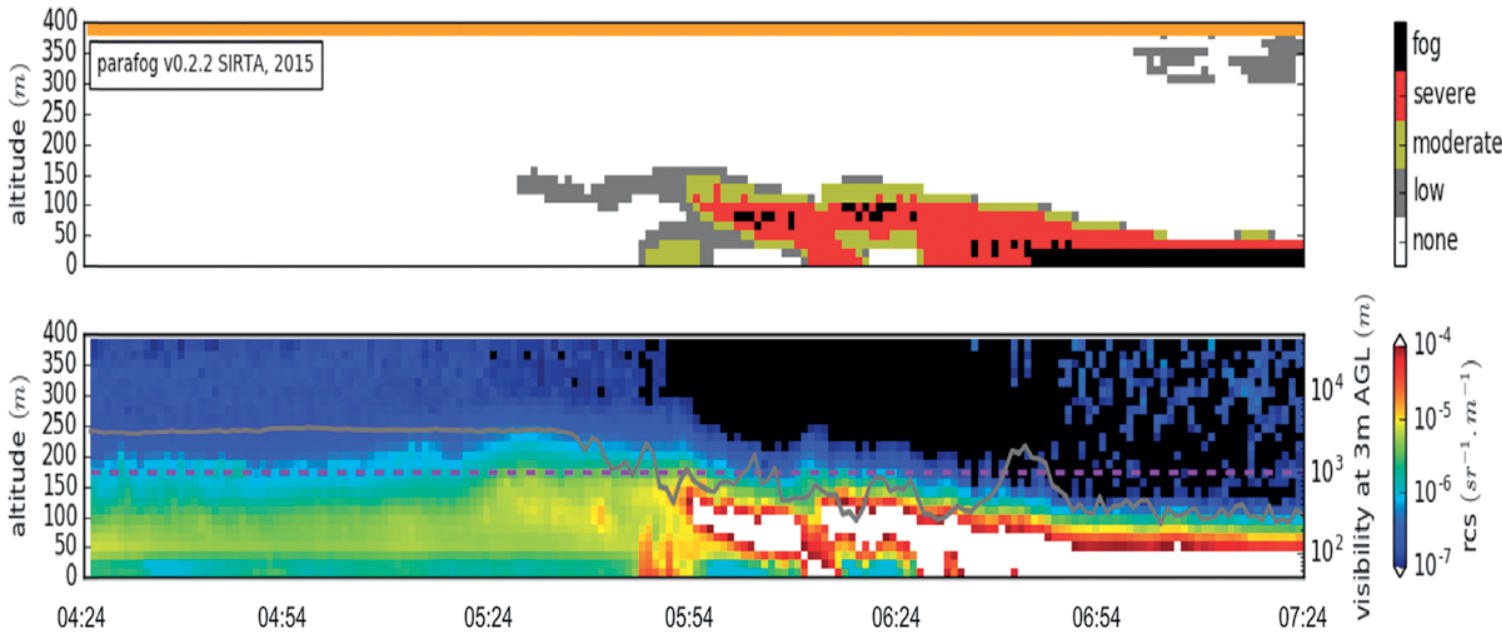

Time UTC - 2016-01-21

Fig. 5. The 3-h time series plot generated automatically from measurements taken at Charles de Gaulle airport on 2I Jan 2016. (top) Fog alerts based on the method of Haeffelin et al. (2016). (bottom) The 0-400-m ALC attenuated backscatter profile $\left(\mathrm{m}^{-1} \mathrm{sr}^{-1}\right.$; shown on a colored log scale) and horizontal visibility close to the surface $(\mathrm{m}$; shown as a gray line; the vertical axis shows the visibility on a log scale). The I-km horizontal-visibility threshold, adopted by WMO to define fog, is shown as a gray dashed line. Plots generated in real time are available online (at www.Imd.polytechnique.fr/ sirta/parafog/). 
where the wind speed and direction are derived from the radial (line of sight) components from off-zenith dwells at different azimuths, or by using a conical velocity-azimuth display (VAD) scan, where the wind speed and direction can be inferred from the magnitude and phase of the sinusoidal azimuthal variation of the observed radial component of the wind. Both methods rely on assuming horizontal homogeneity in order to derive the horizontal component; this may not be applicable in strongly turbulent situations or in flows over complex terrain. TOPROF recommends performing a VAD scan with a minimum of 12 beams and using the method of Päschke et al. (2015), which, in addition to generating the horizontal wind profile, provides a metric describing the likelihood of inhomogeneity degrading the retrieval. Teschke and Lehmann (2017) note that the optimal elevation angle for a VAD scan is about $35^{\circ}$ from horizontal but that this is not a strong constraint; suitable elevation angles for VAD scanning lie between $15^{\circ}$ and $70^{\circ}$ from horizontal. Hence, TOPOROF recommends performing two VAD scans: a primary scan at high elevation $\left(50^{\circ}-70^{\circ}\right.$ from horizontal) to capture the wind profile to the top of the boundary layer and a rapid low-elevation scan at $15^{\circ}$ or lower in elevation (dependent on local obstructions), from which the vertical profile can be extended down toward the surface below the minimum altitude probed by the higher-elevation scan. The inclusion of an additional scan at a low elevation can also be used to investigate the spatial representativeness of the wind profile.

Such high-vertical-resolution wind profiles are ideal for capturing the presence of wind shear, and low-level jets, an important consideration for wind energy, aviation, and air quality applications. An objective method for diagnosing low-level jets was developed (Tuononen et al. 2017) and is now being implemented routinely at a number of sites (Marke et al. 2018). Vertical dwells with high temporal resolution ( $5 \mathrm{~s}$ or better) within the VAD scans allow the retrieval of turbulent parameters such as vertical velocity variance, skewness, and dissipation rate of turbulent kinetic energy (O'Connor et al. 2010). Combining these parameters permits a classification of the atmospheric boundary layer structure (Manninen et al. 2018) in which the turbulent regions are detected, and a probable source of turbulence assigned: for example, whether wind shear or buoyancy production dominates or whether convection is surface driven or cloud driven. The classification scheme also notes whether the turbulent layers are in contact with the surface, an important distinction when calculating dispersion in chemical transport models. Turbulent parameters can also be derived from VAD scans (Vakkari et al. 2015), reconstructed using a stochastic particle filter (Rottner et al. 2017), and the combination of winds and turbulence can be used to diagnose wind gusts (Suomi et al. 2017), especially important in forecasting and assessing wind-induced damage.

DWL products can be used to validate the boundary layer schemes employed in forecast models, even in challenging locations (a coastal example is given in Fig. 6), and to evaluate the much more spatially dense ALC retrievals (Schween et al. 2014). Generating these new products routinely requires that DWL uncertainties are known and well characterized. Known hard targets such as towers and masts can be used to check the radial Doppler velocity and that the pointing angle is correct. Azimuthal pointing repeatability for these instruments was shown to be excellent, typically within $0.25^{\circ}$. Uncertainties in radial Doppler velocity estimates are a function of the number of pulses sampled and their signal-to-noise ratio (SNR). TOPROF worked together with the manufacturers on understanding and improving the data processing to yield reliable data. Reducing the median bias in SNR to about 0.0002 led to improvements in sensitivity by as much as a factor of 5-10 (Manninen et al. 2016) so that a lower SNR threshold could be used to diagnose "good" data. The bias reduction permits more reliable uncertainty estimates, yielding more accurate turbulent parameters. Long-term comparisons of the resulting wind estimates compare very well with masts and other measurements at high SNR with root-mean-square errors (rmses) of $<0.7 \mathrm{~m} \mathrm{~s}^{-1}$ for wind speed and $<10^{\circ}$ for direction (e.g., Päschke et al. 2015), but care should be taken when calculating wind climatologies in low-SNR conditions (Gryning et al. 2016). Now that the data quality has been confirmed, the next step is to establish the $O-B$ statistics. In principle, DWLs provide profiles of attenuated backscatter similar to ALCs. DWLs operating with a telescope focused at infinity can use the same liquid cloud method as for ALCs (Westbrook et al. 2010) for calibrating the backscatter power. However, by adjusting the telescope focus, extra sensitivity in the boundary layer can be achieved while sacrificing sensitivity in the far range, beneficial for retrieving winds and turbulence in the boundary layer but more difficult to account for in calculating the profile of attenuated backscatter. Extensive comparisons have confirmed the accuracy of the winds derived from DWLs, and a more comprehensive $O-B$ comparison is planned using the 2-yr dataset obtained from the DWL network. 

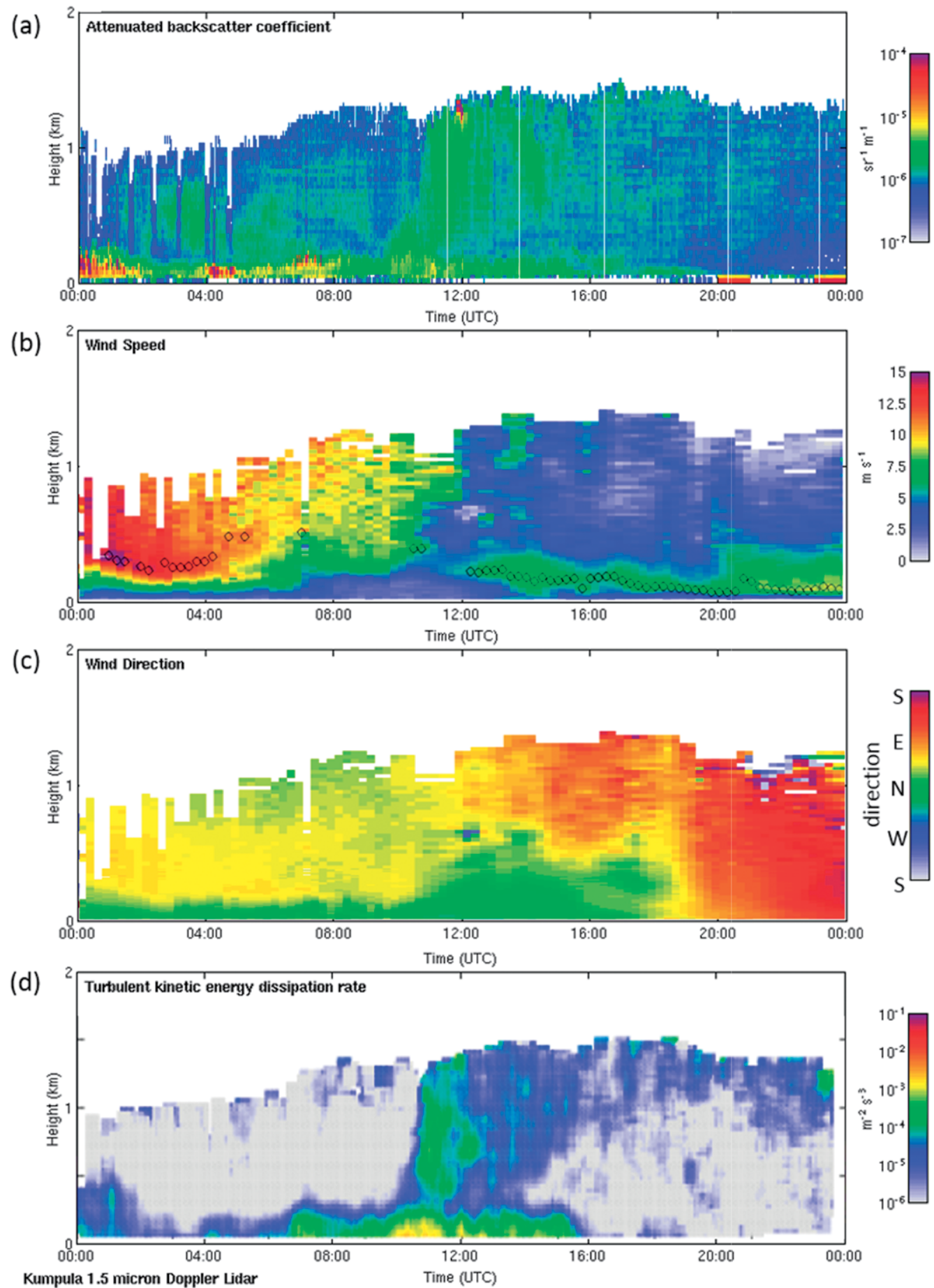

Fig. 6. The 24-h time-height plots of Doppler lidar products generated from a Halo Photonics Streamline operating in Helsinki, Finland, on 24 Mar 2014: (a) attenuated backscatter coefficient, (b) wind speed including objective low-level jet diagnosis (black circles), (c) wind direction, and (d) dissipation rate of turbulent kinetic energy. The wind profiles are obtained from scans at two elevations: $15^{\circ}$ and $70^{\circ}$ from horizontal. Helsinki is situated on a coastline that is aligned approximately east-west, and the Doppler lidar is located about $6 \mathrm{~km}$ inland from the coast. This combination of products illustrates the complexity of the boundary layer in a coastal and urban environment, with a sea breeze driving a marine boundary layer inland (northerly low-level flow from sea to land) underneath a much deeper land boundary layer (more southerly flow from land to sea aloft). Solar noon is around 1000 UTC, and after 1900 UTC, all flow is from land to sea. 
MWRS. MWRs measure downwelling radiation in terms of atmospheric brightness temperatures $T_{B}$ that are then converted to atmospheric variables of interest. TOPROF fostered breakthrough developments in both MWR hardware and software leading to more accurate $T_{B}$ observations, relevant for direct data assimilation, and also to improved retrievals of atmospheric variables. The instruments considered here are multichannel temperature and humidity profilers operating in the 22-31- (humidity) and 51-60-GHz (temperature) bands, such as Radiometer Physics, GmbH (RPG; www.radiometer-physics.de /products/microwave-remote-sensing-instruments /radiometers/humidity-and-temperature-profilers/), Humidity and Temperature Profiler (HATPRO) and Radiometrics MP3000 (http://radiometrics.com/mp -series/; Ware et al. 2003; Rose et al. 2005; De Angelis et al. 2017). These instruments also provide the IWV and cloud LWP.

Two joint calibration (JCAL) field experiments were organized in cooperation with leading MWR manufacturers, triggering the development of new calibration targets and receiver technology. RPG has developed a new arrangement for the liquid nitrogen calibration target that eliminates calibration uncertainties due to reflections and standing waves and provides absolute accuracies of $T_{B}$ on the order of $0.1 \mathrm{~K}$, which is a factor of $\sim 5$ more accurate than previous targets. The load was introduced with the fifthgeneration HATPRO, which also includes an improved receiver technology resulting in $T_{B}$ noise levels also on the order of $0.1 \mathrm{~K}$ at 1-s temporal resolution. Czekala et al. (2017) have shown that this can lead to an uncertainty reduction of the temperature profile retrieval by up to $0.3 \mathrm{~K}$, leading to more reliable detection of temperature inversions in the boundary layer. These hardware developments can also improve the accuracy of IWV and LWP retrievals by up to $50 \%$. The new calibration load is also compatible with radiometers of older generations. Recommendations for operational calibration, measurement, and quality procedures suited for network operation were agreed upon and distributed (http://cetemps.aquila.infn.it/mwrnet /reports.html). In addition, a software package for data postprocessing including retrieval application, quick-look generation, and output conversion (compliant with the Climate and Forecast metadata convention) for most common MWR types is available

(http://cetemps.aquila.infn it/mwrnet/mwr_pro.html).

A fast-forward model has been developed (De Angelis et al. 2016) by adapting existing software widely used for satellite data assimilation so that it can calculate the downwelling $T_{B}$ that would be observed at the ground and their Jacobians from any source of atmospheric temperature and humidity profiles (e.g., radiosondes or an NWP model). The software, Radiative Transfer for the Television and Infrared Observation Satellite (TIROS) Operational Vertical Sounder, ground-based version (RTTOV-gb; http://cetemps.aquila.infn it/mwrnet/rttovgb.html), is freely available, and validation with a reference line-by-line (LBL) computation shows unbiased rms 
differences within $0.2 \mathrm{~K}$, so the error of the parameterized forward model is within the instrumental uncertainty. To monitor the behavior of continuous $T_{B}$ observations, $O-B$ statistics were computed for a 1-yr dataset from a prototype network of six MWRs (De Angelis et al. 2017). Within this network, standardized calibration procedures and data life cycle had been implemented so that quality-controlled data were collected. The six prototype network stations are located at Cabauw, Netherlands $\left(51.97^{\circ} \mathrm{N}\right.$, $4.93^{\circ} \mathrm{E}$ ); Jülich, Germany $\left(50.91^{\circ} \mathrm{N}, 6.41^{\circ} \mathrm{E}\right)$; Leipzig,

Germany $\left(51.35^{\circ} \mathrm{N}, 12.43^{\circ} \mathrm{E}\right)$; Lindenberg, Germany $\left(52.21^{\circ} \mathrm{N}, 14.12^{\circ} \mathrm{E}\right)$; Palaiseau, France $\left(48.40^{\circ} \mathrm{N}\right.$, $\left.2.36^{\circ} \mathrm{E}\right)$; and Payerne, Switzerland $\left(46.82^{\circ} \mathrm{N}, 6.95^{\circ} \mathrm{E}\right)$. Figure 7 shows the 1 -yr time series of $O-B$ comparison at one site for four frequency channels. The NWP model used here is Application of Research to Operations at Mesoscale (AROME), developed by Météo-France (Seity et al. 2011).

The $O-B$ analysis revealed that typical differences are within the expected total uncertainty and that the $O-B$ distributions were Gaussian, confirming their suitability for variational data assimilation. The analysis also demonstrated how such monitoring is able to detect an instrument malfunction leading to a miscalibration and then to verify that a recalibration has been successful as described in Fig. 7. The $O-B$ analysis showed consistent characteristics over time and instrument site/type with a typical $O-B$ bias for well-maintained instruments being generally below $1 \mathrm{~K}$ but reaching $\sim 3 \mathrm{~K}$ at lowerfrequency oxygen channels, where the forward model uncertainty reaches its maximum (De Angelis et al. 2017; Cimini et al. 2018). However, even these uncertainties can be effectively addressed because the biases were persistent and the random component was similar throughout the prototype network. The uncertainty of the reference LBL calculations have also been investigated (Cimini et al. 2018), possibly explaining systematic $O-B$ differences exceeding $1 \mathrm{~K}$ that must be accounted for within a bias correction scheme. A platform for continuously monitoring $O-B$ quick looks in near-real time is up and running and available for all interested users (https://tinyurl.com/MWR-O-B-JOYCE). The main goal of this platform is i) to provide an independent instrument performance monitoring tool for MWR operators and ii) to attest the suitability of MWR for operational use by national weather services.

In addition to the prototype network, there are some 30 MWR stations over Europe that have the potential to deliver $T_{B}$ values and derived products on a continuous basis. Details of the network can be found online (at http://cetemps.aquila.infn.it /mwrnet/MWRnetmap.html). Long data records (exceeding 10 years) are available from some of these sites, in Europe (e.g., Lindenberg, Payerne, and Potenza) as well as in the United States [e.g., Atmospheric Radiation Measurement (ARM) sites; Cadeddu et al. 2013].

MWR data assimilation promises to be useful for adjusting NWP model temperature and humidity fields of the lowest $2 \mathrm{~km}$, especially in convective (Cimini et al. 2015) and very stable conditions (Martinet et al. 2017). Figure 8 shows how the assimilation of MWR brightness temperatures leads to an improvement in the temperature analysis in an enclosed Alpine valley during stable conditions where the true structure has been established from a series of radiosonde ascents; the stability close to the ground is a crucial parameter in the buildup and dispersion of pollutants. Similarly, Fig. 9 shows large potential improvements in both temperature and humidity 

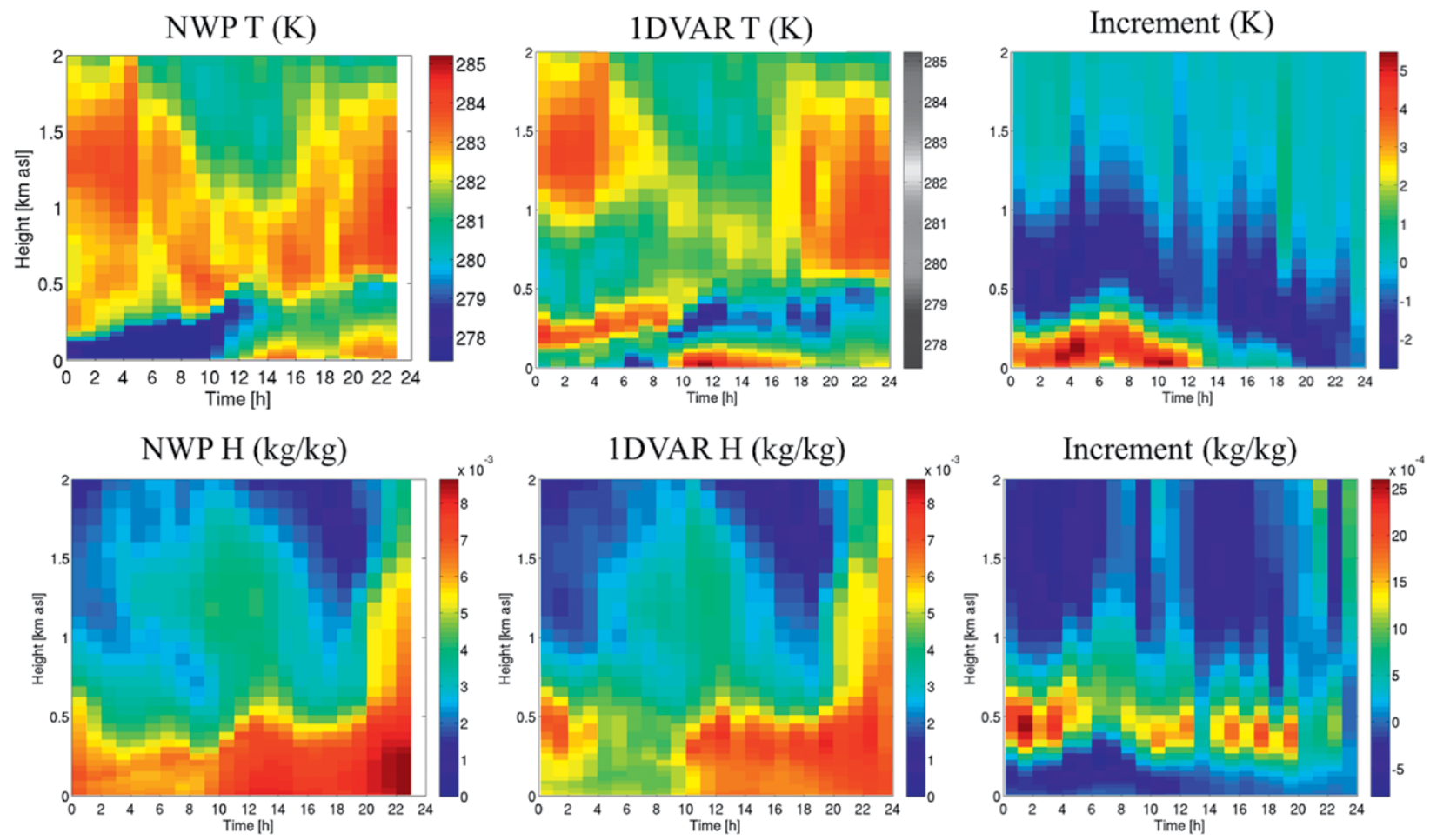

FIG. 9. The 24-h time series (28 Oct 20I6) of (top) temperature and (bottom) humidity from (left) AROME NWP model, (center) IDVAR analysis update, and (right) the difference between the two showing temperature increments of up to $5 \mathrm{~K}$. Data from a fog field campaign at Observatoire Perenne de l'Environnement (48.5 ${ }^{\circ} \mathrm{N}$, $5.50^{\circ} \mathrm{E}$; alt: $388 \mathrm{~m}$ ) near Bure, France. The campaign extended from Sep 2016 to Apr 2017 and included one MWR unit. NWP system is AROME I-h forecast cycle, I.3-km horizontal resolution, 90 vertical levels. The nearest gridpoint I-h forecast is used as background for the IDVAR retrievals at I-h resolution, based on the closest measurements within $15 \mathrm{~min}$.

profiles when observations from one MWR are used to correct the NWP forecast one-dimensional variational data assimilation (1DVAR) retrieval scheme. The 24-h time series of temperature and humidity profiles from an NWP forecast, 1DVAR retrievals, and the analysis increment are shown. Based on these results, Météo-France decided to deploy an MWR network for an international fog field campaign planned for October 2019-April 2020 (eight to ten MWR units in a $300 \mathrm{~km} \times 200 \mathrm{~km}$ domain). Forecast indices derived from MWR observations were also demonstrated to be useful in support of nowcasting and short-range weather forecasting (Cimini et al. 2015). Continentalscale data assimilation trials show positive-to-neutral impact, especially for accumulations of precipitation up to $18 \mathrm{~h}$ after forecast initialization (Caumont et al. 2016). The impact of MWR-derived thermodynamic profiles is larger when they are used to substitute classical radiosonde observations in a data denial experiment. Data assimilation results obtained so far did not take advantage of the recent hardware and software developments, so there is clearly potential for improvement.
CONCLUSIONS. Networks of ground-based profiling instruments with improved retrieval algorithms and standardized software and calibration procedures have been developed by TOPROF in collaboration with instrument manufacturers and implemented by the E-PROFILE program of the EUMETNET consortium of European national weather services. These networks are providing an increased understanding of process within the lowest few kilometers of the atmosphere and, ultimately, have the potential for assimilation into operational NWP models. Improvements have been made in the automatic lidar and ceilometer (ALC) algorithms that correct for overlap, remove artifacts in the profiles, and provide absolute backscatter calibration to within $\sim 10 \%$ using natural targets as a reference, either the integrated backscatter from thick water clouds or the molecular return. The network has the demonstrated capability for tracking smoke from forest fires and desert dust, issuing fog formation warnings, and providing vertical profiles of cloud and aerosols. An $O-B$ comparison of the observed backscatter from desert dust with those from an ECMWF forward model indicates that 
biases are below $10 \%$. Profiles of aerosol and cloud backscatter from a network of 265 ALCs (as of April 2019) are being distributed in real time to European weather forecast centers, and this should increase to several hundred within the next year.

A network of Doppler wind lidars (DWLs) is being integrated into the wind network of E-PROFILE during the current program phase 2019-2023 and will be distributed to forecast centers. DWLs use aerosol or cloud particles as tracers of the line of sight component of atmospheric motion. Standardized scanning procedures and algorithms have been established so they can routinely provide data on wind profiles in the boundary layer with an $\mathrm{rms}$ accuracy of $<10^{\circ}$ in direction and better than $0.7 \mathrm{~m} \mathrm{~s}^{-1}$ in speed. These observations can be used for diagnosis of the existence of low-level jets, deriving profiles of vertical velocity variance and skewness, and the dissipation rate of turbulent kinetic energy. The combination of the wind and turbulence can be used to diagnose wind gusts, needed for forecasting and assessing wind-induced damage, and for classification of the atmospheric boundary layer structure so that those turbulent layers in contact with the surface can be identified; this is an important property when calculating the dispersion by chemical transport models.

TOPROF studies have led to advances in microwave radiometer (MWR) hardware and software so the instruments can provide brightness temperature $T_{B}$ calibrations to within $0.1 \mathrm{~K}$. A ground-based version of the RTTOV radiative transport model has been developed and characterized so that $T_{B}$ and its uncertainty can be calculated from a forecast model. Tests over one year comparing these forward-modeled values of $T_{B}$ with those observed with a prototype network of six MWRs show that typical $O-B$ biases for well-maintained instruments are generally below $1 \mathrm{~K}$. Field campaigns have demonstrated that the assimilation of $T_{B}$ into an operational mesoscale model leads to improved temperature and humidity structure in the lowest $2 \mathrm{~km}$ of the atmosphere. E-PROFILE is evaluating the extension of their activities to MWR so that data can be distributed in real time to European weather forecast centers starting from 2020.

ACKNOWLEDGMENTS. This article/publication is based upon work from COST Action ES1303 "TOPROF" supported by COST (www.cost.eu).

\section{REFERENCES}

Baars, H., and Coauthors, 2016: An overview of the first decade of Polly ${ }^{\mathrm{NET}}$ : An emerging network of automated Raman-polarization lidars for continuous aerosol profiling. Atmos. Chem. Phys., 16, 5111-5137, https://doi.org/10.5194/acp-16-5111-2016.

Benedetti, A., and Coauthors, 2009: Aerosol analysis and forecast in the European Centre for MediumRange Weather Forecasts Integrated Forecast System: 2. Data assimilation. J. Geophys. Res., 114, D13205, https://doi.org/10.1029/2008JD011115.

Cadeddu, M. P., J. C. Liljegren, and D. D. Turner, 2013: The Atmospheric Radiation Measurement (ARM) program network of microwave radiometers: Instrumentation, data, and retrievals. Atmos. Meas. Tech., 6, 2359-2372, https://doi.org/10.5194/amt-6 $-2359-2013$.

Caumont, O. D., and Coauthors, 2016: Assimilation of humidity and temperature observations retrieved from ground-based microwave radiometers into a convective-scale model. Quart. J. Roy. Meteor. Soc., 142, 2692-2704, https://doi.org/10.1002/qj.2860.

Cazorla, A., and Coauthors, 2017: Near-real-time processing of a ceilometer network assisted with sun-photometer data: Monitoring a dust outbreak over the Iberian Peninsula. Atmos. Chem. Phys., 17, 11 861-11 876, https://doi.org/10.5194/acp-17 $-11861-2017$.

Chan, K. L., M. Wiegner, H. Flentje, I. Mattis, F. Wagner, J. Gasteiger, and A. Geiß, 2018: Evaluation of ECMWF-IFS (version 41R1) operational model forecasts of aerosol transport by using ceilometer network measurements. Geosci. Model Dev., 11, 3807-3831, https://doi.org/10.5194/gmd-11-3807 -2018 .

Cimini, D., M. Nelson, J. Güldner, and R. Ware, 2015: Forecast indices from a ground-based microwave radiometer for operational meteorology. Atmos. Meas. Tech., 8, 315-333, https://doi.org/10.5194 lamt-8-315-2015.

—, P. W. Rosenkranz, M. Y. Tretyakov, M. A. Koshelev, and F. Romano, 2018: Uncertainty of atmospheric microwave absorption model: Impact on ground-based radiometer simulations and retrievals. Atmos. Chem. Phys., 18, 15231-15259, https://doi .org/10.5194/acp-18-15231-2018.

Czekala D., and Coauthors, 2017: Ground based microwave radiometers: Noise performance, calibration performance and data Formats for DA. Proc. Seventh Int. WMO Symp. on Data Assimilation, Florianopolis, Brazil, World Meteorological Organization, www .cptec.inpe.br/das2017/.

De Angelis, F., D. Cimini, J. Hocking, P. Martinet, and S. Kneifel, 2016: RTTOV-gb-Adapting the fast radiative transfer model RTTOV for the assimilation of ground-based microwave radiometer observations. 
Geosci. Model Dev., 9, 2721-2739, https://doi.org /10.5194/gmd-9-2721-2016.

— , and Coauthors, 2017: Long-term observations minus background monitoring of ground-based brightness temperatures from a microwave radiometer network. Atmos. Meas. Tech., 10, 3947-3961, https://doi.org/10.5194/amt-10-3947-2017.

Fernald, F. G., B. M. Herman, and J. A. Reagan, 1972: Determination of aerosol height distributions by lidar. J. Appl. Meteor., 11, 482-489, https://doi.org/10.1175 /1520-0450(1972)011<0482:DOAHDB>2.0.CO;2.

Gryning, S. E., R. Floors, A. Peña, E. Batchvarova, and B. Brümmer, 2016: Weibull wind-speed distribution parameters derived from a combination of wind-lidar and tall-mast measurements over land, coastal and marine sites. Bound.-Layer Meteor., 159, 329-348, https://doi.org/10.1007/s10546-015-0113-x.

Haeffelin, M., and Coauthors, 2012: Evaluation of mixing height retrievals from automatic profiling lidars and ceilometers in view of future integrated networks in Europe. Bound.-Layer Meteor., 143, 49-75, https:// doi.org/10.1007/s10546-011-9643-z.

—, Q. Laffineur, J.-A. Bravo-Aranda, M.-A. Drouin, J.-A. Casquero-Vera, J.-C. Dupont, and H. De Backer, 2016: Radiation fog formation alerts using attenuated backscatter power from automatic lidars and ceilometers. Atmos. Meas. Tech., 9, 5347-5365, https://doi .org/10.5194/amt-9-5347-2016.

Hervo, M., Y. Poltera, and A. Haefele, 2016: An empirical method to correct for temperature-dependent variations in the overlap function of CHM15k ceilometers. Atmos. Meas. Tech., 9, 2947-2959, https://doi .org/10.5194/amt-9-2947-2016.

Hopkin, E, A. J. Illingworth, C. Charlton-Perez, C. D. Westbrook, and S. Ballard, 2018: A robust automated technique for operational calibration of ceilometers using the integrated backscatter from totally attenuating liquid clouds. Atmos. Meas. Tech. Discuss., https://doi.org/10.5194/amt-2018-427.

Illingworth, A. J., and Coauthors, 2007: Cloudnet: Continuous evaluation of cloud profiles in seven operational models using ground-based observations. Bull. Amer. Meteor. Soc., 88, 883-898, https:// doi.org/10.1175/BAMS-88-6-883.

—, D. Cimini, C. Gaffard, M. Haeffelin, V. Lehmann, U. Löhnert, E. J. O’Connor, and D. Ruffieux, 2015: Exploiting existing ground-based remote sensing networks to improve high-resolution weather forecasts. Bull. Amer. Meteor. Soc., 96, 2107-2125, https:// doi.org/10.1175/BAMS-D-13-00283.1.

Klett, J. D., 1985: Lidar inversion with variable backscatter extinction ratios. Appl. Opt., 24, 1638-1643, https://doi.org/10.1364/AO.24.001638.
Kotthaus, S., and C. S. B. Grimmond, 2018: Atmospheric boundary layer characteristics from ceilometer measurements. Part 1: A new method to track mixed layer height and classify clouds. Quart. J. Roy. Meteor. Soc., 144, 1525-1538, https://doi.org/10.1002/qj .3299 .

—, E. O’Connor, C. Münkel, C. Charlton-Perez, M. Haeffelin, A. M. Gabey, and C. S. B. Grimmond, 2016: Recommendations for processing atmospheric attenuated backscatter profiles from Vaisala CL31 ceilometers. Atmos. Meas. Tech., 9, 3769-3791, https://doi.org/10.5194/amt-9-3769-2016.

Lotteraner, C., and M. Piringer, 2016: Mixing-height time series from operational ceilometer aerosol-layer heights. Bound.-Layer Meteor., 161, 265-287, https:// doi.org/10.1007/s10546-016-0169-2.

Manninen, A. J., E. J. O’Connor, V. Vakkari, and T. Petäjä, 2016: A generalised background correction algorithm for a Halo Doppler lidar and its application to data from Finland. Atmos. Meas. Tech., 9, 817-827, https://doi.org/10.5194/amt-9-817-2016.

—, T. Marke, M. Tuononen, and E. J. O'Connor, 2018: Atmospheric boundary layer classification with Doppler lidar. J. Geophys. Res. Atmos., 123, 8172-8189, https://doi.org/10.1029/2017JD028169.

Marke, T., S. Crewell, V. Schemann, J. H. Schween, and M. Tuononen, 2018: Long-term observations and high-resolution modeling of midlatitude nocturnal boundary layer processes connected to low-level jets. J. Appl. Meteor. Climatol., 57, 1155-1170, https://doi .org/10.1175/JAMC-D-17-0341.1.

Martinet, P. D., D. Cimini, F. De Angelis, G. Canut, V. Unger, R. Guillot, D. Tzanos, and A. Paci, 2017: Combining ground-based microwave radiometer and the AROME convective scale model through 1 DVAR retrievals in complex terrain: An Alpine valley case study. Atmos. Meas. Tech., 10, 3385-3402, https://doi.org/10.5194/amt-10-3385 $-2017$.

O’Connor, E. J., A. J. Illingworth, and R. J. Hogan, 2004: A technique for autocalibration of cloud lidar. J. Atmos. Oceanic Technol., 21, 777-786, https://doi .org/10.1175/1520-0426(2004)021<0777:ATFAOC $>2.0 . \mathrm{CO} ; 2$.

,-- I. M. Brooks, C. D. Westbrook, R. J. Hogan, F. Davies, and B. J. Brooks, 2010: A method for estimating the turbulent kinetic energy dissipation rate from a vertically pointing Doppler lidar, and independent evaluation from balloon-borne in-situ measurements. J. Atmos. Oceanic Technol., 27, 1652-1664, https://doi.org/10.1175/2010JTECHA1455.1.

Päschke, E., R. Leinweber, and V. Lehmann, 2015: An assessment of the performance of a $1.5 \mu \mathrm{m}$ Doppler 
lidar for operational vertical wind profiling based on a 1-year trial. Atmos. Meas. Tech., 8, 2251-2266, https://doi.org/10.5194/amt-8-2251-2015.

Pattantyús-Ábrahám, M., and Coauthors, 2017: The dataset of the CeiLinEx 2015 Ceilometer-InterComparison Experiment, version 001. Deutscher Wetterdienst, accessed 20 February 2019, https://doi .org/10.5676/DWD/CEILINEX2015.

Poltera, Y., G. Martucci, M. Collaud Coen, M. Hervo, L. Emmenegger, S. Henne, D. Brunner, and A. Haefele, 2017: Pathfinder TURB: An automatic boundary layer algorithm. Development, validation and application to study the impact on in-situ measurements at the Jungfraujoch. Atmos. Chem. Phys., 17, 10 051-10 070, https://doi.org/10.5194/acp-17-10051 $-2017$.

Román, R., and Coauthors, 2018: Retrieval of aerosol profiles combining sunphotometer and ceilometer measurements in GRASP code. Atmos. Res., 204, 161177, https://doi.org/10.1016/j.atmosres.2018.01.021.

Rose, T., S. Crewell, U. Löhnert, and C. Simmer, 2005: A network suitable microwave radiometer for operational monitoring of the cloudy atmosphere. Atmos. Res., 75, 183-200, https://doi.org/10.1016/j .atmosres.2004.12.005.

Rottner, L., C. Baehr, A. Dabas, and L. Hammoud, 2017: Stochastic method for turbulence estimation from Doppler lidar measurements. J. Appl. Remote Sens., 11, 046001, https://doi.org/10.1117/1.JRS.11.046001.

Schween, J. H., A. Hirsikko, U. Löhnert, and S. Crewell, 2014: Mixing layer height retrieval with ceilometer and Doppler lidar: From case studies to long-term assessment. Atmos. Meas. Tech., 7, 3685-3704, https://doi.org/10.5194/amt-7-3685-2014.

Seity, Y., P. Brousseau, S. Malardel, G. Hello, P. Bénard, F. Bouttier, C. Lac, and V. Masson, 2011: The AROME-France convective-scale operational model. Mon. Wea. Rev., 139, 976-991, https://doi .org/10.1175/2010MWR3425.1.

Suomi, I., S.-E. Gryning, E. J. O'Connor, and T. Vihma, 2017: Methodology for obtaining wind gusts using
Doppler lidar. Quart. J. Roy. Meteor. Soc., 143, 2061-2072, https://doi.org/10.1002/qj.3059.

Teschke, G., and V. Lehmann, 2017: Mean wind vector estimation using the velocity-azimuth display (VAD) method: An explicit algebraic solution. Atmos. Meas. Tech., 10, 3265-3271, https://doi.org/10.5194/amt -10-3265-2017.

Tuononen, M., E. J. O'Connor, V. A. Sinclair, and V. Vakkari, 2017: Low-level jets over Utö, Finland, based on Doppler lidar observations. J. Appl. Meteor. Climatol., 56, 2577-2594, https://doi.org/10.1175 /JAMC-D-16-0411.1.

Vakkari, V., E. J. O'Connor, A. Nisantzi, R. E. Mamouri, and D. G. Hadjimitsis, 2015: Low-level mixing height detection in coastal locations with a scanning Doppler lidar. Atmos. Meas. Tech., 8, 1875-1885, https://doi.org/10.5194/amt-8-1875-2015.

Ware, R., R. Carpenter, J. Güldner, J. Liljegren, T. Nehrkorn, F. Solheim, and F. Vandenberghe, 2003: A multichannel radiometric profiler of temperature, humidity, and cloud liquid. Radio Sci., 38, 8079, https://doi.org/10.1029/2002RS002856.

Warren, E., C. Charlton-Perez, S. Kotthaus, H. Lean, S. Ballard, E. Hopkin, and S. Grimmond, 2018: Evaluation of forward-modelled attenuated backscatter using an urban ceilometer network in London under clear-sky conditions. Atmos. Environ., 191, 532-547, https://doi.org/10.1016/j.atmosenv.2018.04.045.

Westbrook, C. D., A. J. Illingworth, E. J. O'Connor, and R. J. Hogan, 2010: Doppler lidar measurements of oriented planar ice crystals falling from supercooled and glaciated cloud layers. Quart. J. Roy. Meteor. Soc., 136, 260-276, https://doi.org/10.1002/qj.528.

Wiegner, M., and A. Geiß, 2012: Aerosol profiling with the Jenoptik ceilometer CHM15kx. Atmos. Meas. Tech., 5, 1953-1964, https://doi.org/10.5194/amt-5 -1953-2012.

— - and J. Gasteiger, 2015: Correction of water vapor absorption for aerosol remote sensing with ceilometers. Atmos. Meas. Tech., 8, 3971-3984, https://doi .org/10.5194/amt-8-3971-2015. 


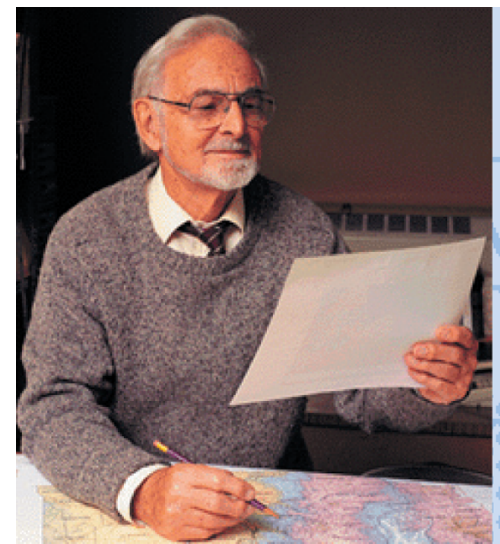

A Half Century of Progress in Meteorology:

A Tribute to Richard Reed

\section{edited by Richard H. Johnson and Robert A. Houze Jr.}

with selections by: Lance F. Bosart Robert W. Burpee Anthony Hollingsworth James R. Holton Brian J. Hoskins Richard S. Lindzen John S. Perry Erik A. Rasmussen Adrian Simmons Pedro Viterbo

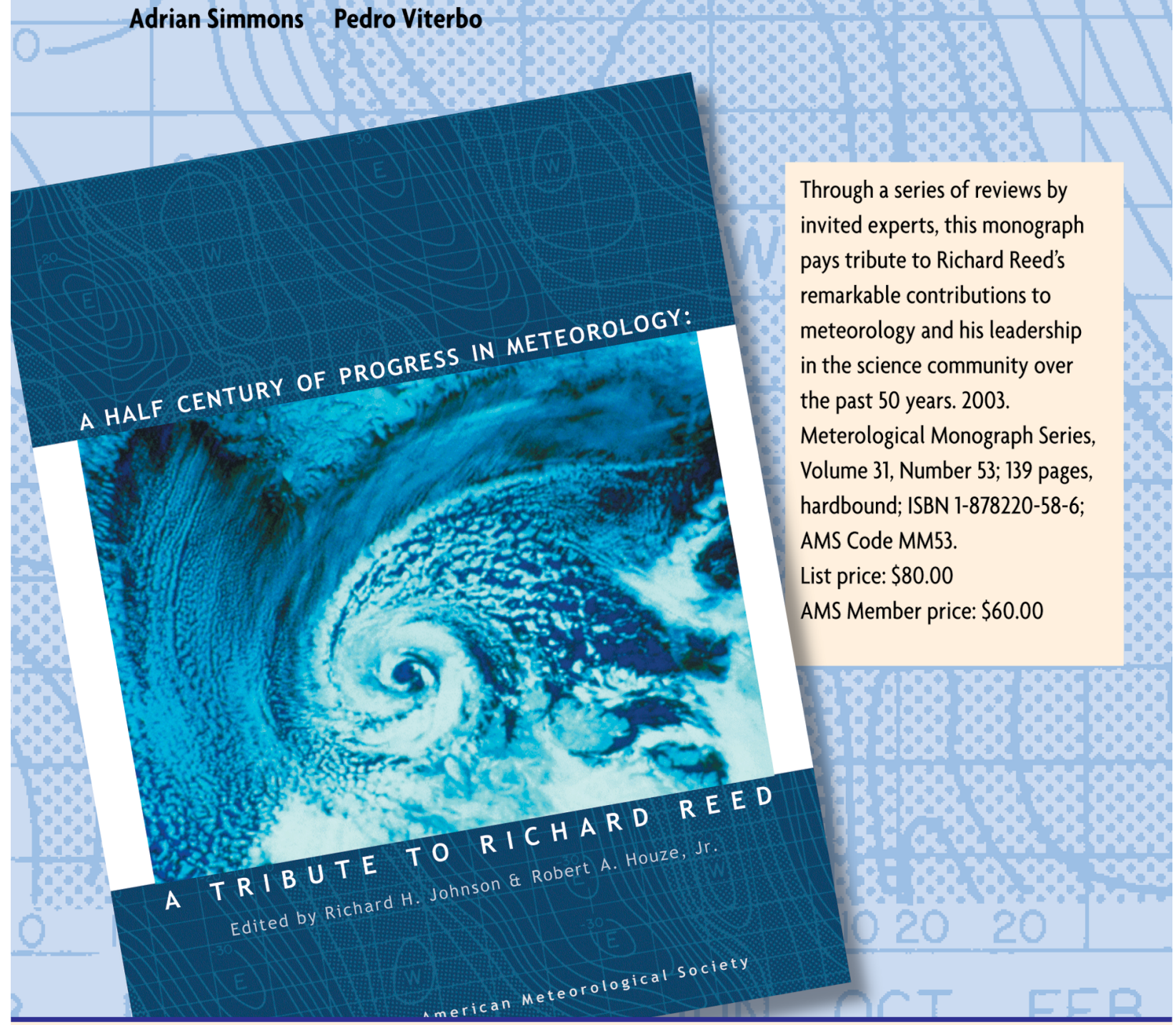

Order Online from bookstore.ametsoc.org 